\title{
Significance of Aspirin on Blood Flow to Prevent Blood Clotting through Inclined Multi-Stenosed Artery
}

\section{Sapna Ratan Shah*}

School of Computational and Integrative Sciences, Jawaharlal Nehru University, New Delhi

*Corresponding author: Sapna Ratan Shah, School of Computational and Integrative Sciences, Jawaharlal Nehru University, New Delhi-110067, India, Fax: 011-2653894; E-mail: sapna1980jan@rediffmail.com

\begin{abstract}
This study has presented the importance of aspirin with blood to prevent blood clotting through a likely multi stenosed artery by using Casson's and Bingham Plastic fluid models. A clot in an artery may stop blood flowing to the tissues further down. In this paper, the equations describing the flow have been solved, and the expressions parameters on flow variables have been studied. The graphical representations have been made to validate the result with a view of its applicability to stenotic diseases. It is found that the flow of resistance increases with the height of the stenosis but decreases with the angle of inclination. Aspirin helps to prevent blood clots forming. A dose of Aspirin will dilute the blood and reduces the blood viscosity as well as lowers the blood pressure. The results shown in this paper are compared with the available results presented by previous research work.
\end{abstract}

Received Date: May 23, 2017

Accepted Date: December 05, 2017

Published Date: December 12, 2017

Citation: Shah, S.P. Significance of Aspirin on Blood Flow to Prevent Blood Clotting through Inclined Multi-Stenosed Artery. (2017) Lett Health Biol Sci 2(2): 97- 100 .

DOI: $10.15436 / 2475-6245.17 .018$

Keywords: Blood flow; Blood vessels; Axially symmetric stenoses; Casson's fluid model; Bingum fluid model; Inclined tube

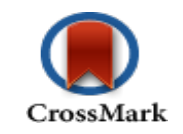

\section{Introduction}

Aspirin is a medicine that is being used for many years as a pain killer. However, it has another action to lower the risk of forming a blood clot in the arteries of the heart (coronary arteries) or brain. This reduces thedanger of having a heart attack or stroke.In medicine, one of the major health hazards is atherosclerosis, which is the leading cause of death in many countries. Atherosclerosis or stenosis is a cardiovascular disease. Cardiovascular diseases are diseases of the heart or blood vessels like arteries, vein and capillaries. However, in practice, when doctors use the term heart disease they usually mean diseases of the heart or blood vessels that are caused by atheromaAtherosclerosis or stenosis. Patches of atheroma are like fatty lumps that develop in the inside lining of some blood vessels (arteries). These diseases include heart attack, angina, stroke, transient ischaemic attack (TIA) and peripheral arterial disease. Stenosis leads to an increase in the resistance to the flow and associated reduction in blood supply in the downstream which also causes hypertension, myocardial infarction, and cerebral strokes, etc ${ }^{[1,2]}$.

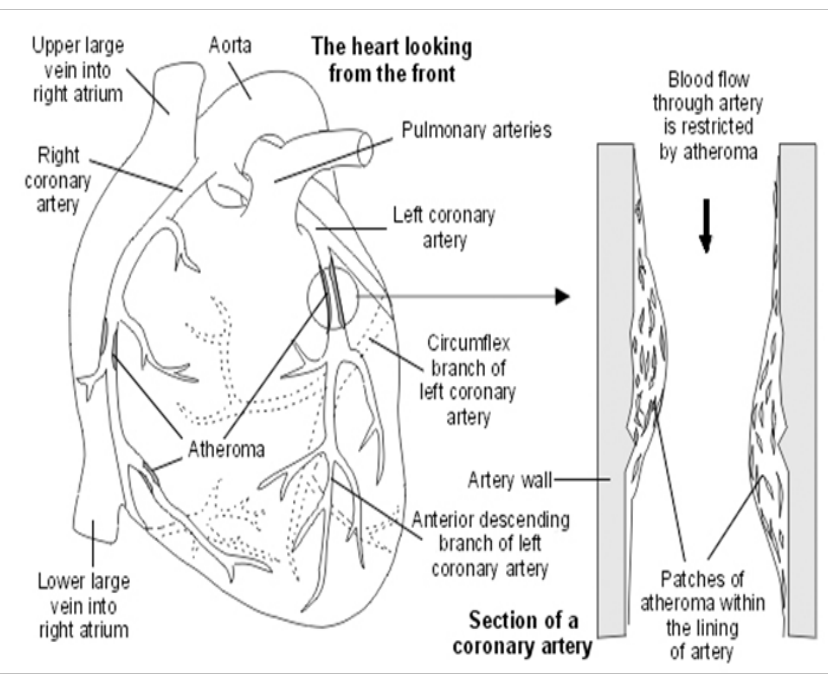

Figure 1: A heart and an artery with atheroma. 
Hence it is essential to study the blood flow through a stenosed artery to prevent the arterial diseases. Most people who have a cardiovascular disease (for example, angina, peripheral arterial disease, or a previous heart attack, transient ischemic attack (TIA) or stroke) take a low-dose aspirin $(75 \mathrm{mg})$ each day or clopidogrel $(75 \mathrm{mg})$ each day. This reduces the risk of having a heart attack by about a third. It reduces thedanger of having a stroke by about a quarter. A daily low dose of aspirin also reduces therisk of developing some common cancers. Given this, several theoretical and mathematical models ${ }^{[3,4]}$ have been developed to study the blood flow characteristics due to the presence of stenosis in the lumen of the blood vessel. Mohan, V., et al $(2013)^{[5]}$ examined the effect of paired stenosis through the small artery. Bhatnagar, A., et al $(2015)^{[6]}$ studied the effects of an overlapping stenosis on blood flow characteristics in a narrow artery. All these investigations have considered the consequences of stenosis through a tube of uniform cross-section. But, it is known that many ducts in physiological systems are not horizontal but have some inclination to the axis. Mekheimer, Kh.S., et al (2012) $)^{[7]}$ studied the flow of Herschel-Bulkley fluid through an inclined tube of the non-uniform cross section with multiple stenoses. This work $^{[8]}$ have analyzed mathematical models by considering blood as a Herschel-Bulkley type on- Newtonian fluid. In a recent paper Ellahi, R., et al (2014) ${ }^{[9]}$ have presented a mathematical model to show the effect of stenosis on Casson flow of blood. A mathematical model of blood flow through irregular arterial mild stenoses is developed by Karimi, $\mathrm{A}^{[2]}$ and studied that if the viscosity of the fluid increases the velocity of fluid decreases in the presence of stenoses. The developed a mathematical model for studying blood flow through a narrow artery with multiple stenoses, and they have observed that stenoses height and axial velocity of flow very much influence the shear stress in a stenosed artery ${ }^{[10]}$. In the present study, we propose to discuss the effects of inclined multi-stenoses arteries on blood flow characteristics using Casson's and Bingham plastic fluid model. Results have been comparing the both fluid model. Mathematical equations have been solved with the help of numerical technique.

\section{Formulation of the problem}

Let us consider an axially symmetric, laminar, fully develop flow of the blood through a tube of non-uniform cross-section and with two stenoses Figure.1, 2.

The momentum equation is given by

$\frac{1}{r} \frac{\partial}{\partial r}\left(r \tau_{r z}\right)=-\frac{\partial p}{\partial z}+\frac{\sin \alpha}{F}$,

$F=\frac{\mu U^{n}}{\rho g R_{0}^{n+1}}$

Where $\tau_{\mathrm{rz}}$ is the shear stress for the fluid, The Casson Fluid model:

$$
\begin{aligned}
\tau_{r z}^{\frac{1}{2}} & =\left[-\mu \frac{\partial u}{\partial r}\right]^{\frac{1}{2}}+\tau_{0}^{\frac{1}{2}}, \tau_{r z}>\tau_{0} \\
\frac{\partial u}{\partial r} & =0, \tau_{r z}<\tau_{0}
\end{aligned}
$$

$$
\begin{aligned}
& \text { The Bingham Plastic Fluid model: } \\
& \tau_{r z}=-\mu \frac{\partial u}{\partial r}+\tau_{0}, \tau_{r z}>\tau_{0} \\
& \frac{\partial u}{\partial r}=0, \tau_{r z}<\tau_{0}
\end{aligned}
$$

The boundary conditions are:

$\tau$ is finite at $r=0$

$\mathrm{u}=0$ at $\mathrm{r}=\mathrm{h}(\mathrm{z})$

For the analysis presented in the sequel, we use the following non-dimensional variable

$\bar{z}=\frac{z}{L}, \bar{\delta}=\frac{\delta}{R_{0}}, \bar{R}(z)=\frac{R(z)}{R_{0}}, \bar{P}=\frac{p}{\left(\frac{\mu U L}{R_{0}^{2}}\right)}, \bar{\tau}_{0}=\frac{\tau_{0}}{\mu\left(\frac{U}{R_{0}}\right)}, \bar{\tau}_{r z}=\frac{\tau_{r z}}{\mu\left(\frac{U}{R_{0}}\right)}, \bar{Q}=\frac{Q}{\pi R_{0}^{2}} \bar{F}=\frac{F}{\mu U \lambda}(9)$

The geometry of the stenoses in non-dimensional form is given by figure 2 .

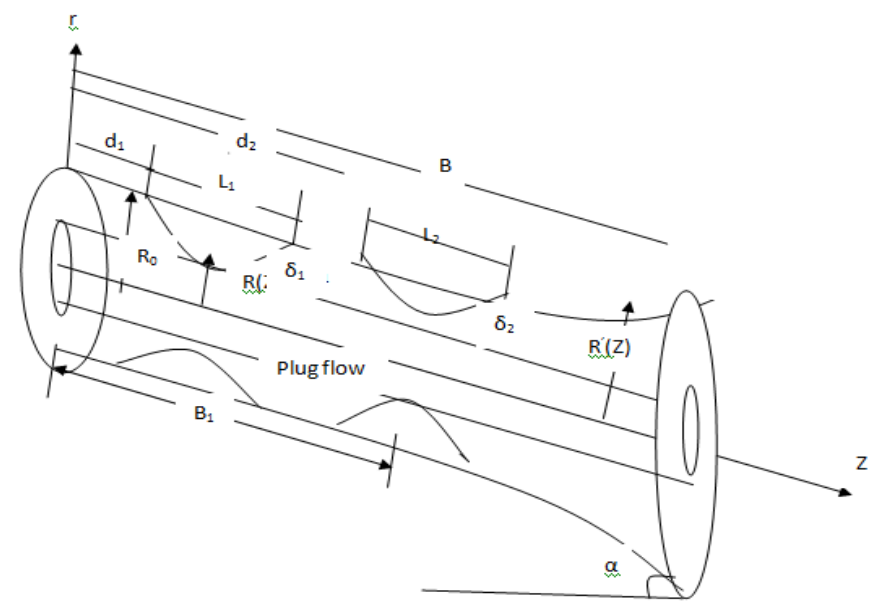

Figure 2: Geometry of an inclined tube with multiple stenosis.

$$
\mathrm{h}=\mathrm{R}(\mathrm{z})=\left\{\begin{array}{c}
R_{0}: 0 \leq z \leq d_{1}, \\
R_{0}-\frac{\delta_{1}}{2}\left(1+\cos \frac{2 \pi}{L_{1}}\left(z-d_{1}-\frac{L_{1}}{2}\right)\right): d_{1} \leq z \leq L_{1}, \\
R_{0}: d_{1}+L_{1} \leq z \leq B_{1}-\frac{L_{2}}{2}, \\
R_{0}-\frac{\delta_{1}}{L_{2}}\left(1+\cos \frac{2 \pi}{L_{2}}\left(z-B_{1}\right)\right): B_{1}-\frac{L_{2}}{2} \leq z \leq B_{1}, \\
R^{*}(z)-\frac{\delta_{1}}{2}\left(1+\cos \frac{2 \pi}{L_{2}}\left(z-B_{1}\right)\right): B_{1} \leq z \leq B_{1}+\frac{L_{2}}{2}, \\
R^{*}(z): B_{1}+\frac{L_{2}}{2} \leq z \leq B,
\end{array}\right.
$$

The following restrictions for mild stenoses are supposed to be satisfied:

$\delta_{\mathrm{i}}<<\min \left(\mathrm{R}_{0}, \mathrm{R}_{\text {out }}\right)$,

$\delta_{\mathrm{i}}<<\mathrm{L}_{\mathrm{i}}$, where $\mathrm{R}_{\text {out }}=\mathrm{R}(\mathrm{z})$ at $\mathrm{z}=\mathrm{B}$.

Here $L_{i}$ and $\delta_{i}$ are the lengths and maximum heights of two stenoses.

\section{Analytical solution of the problem}

Solving Eqs. (1),(3) and (5) under the boundary conditions (7) and (8), we obtain the velocity, when $P=-\partial p / \partial z$, and $f=\sin \alpha / F$. 


$$
\begin{array}{lc}
u=\frac{(P+f)}{\mu}\left[\frac{r^{2}-h^{2}}{4}+\frac{\tau_{0}}{(P+h)}(r-h)-\frac{2 \sqrt[2]{2}}{3}\left(r^{3 / 2}-h^{3 / 2}\right)\left(\frac{\tau_{0}}{(P+f)}\right)^{1 / 2}\right] \\
u=\frac{(P+f)}{\mu}\left[\frac{r^{2}-h^{2}}{4}+\frac{\tau_{0}}{(P+h)}(r-h)\right] \quad \text { for } r_{0} \leq r \leq h
\end{array}
$$

Velocity for the Casson's fluid model is given by Eq. (11), and the speed for the Bingham Plastic fluid model is given by Eq. (12).

Using the condition (14) and (16), we finally get the upper limit of the plug flow region (i.e., the region between $r=0$ and $\mathrm{r}=\mathrm{r}_{\mathrm{n}}$ for which $\left|\tau_{\mathrm{rz}}\right|<\tau_{0}$ ) as

$r_{0}=\frac{2 \tau_{0}}{(p+f)}$

And using the condition $\tau_{r r}=\tau_{\mathrm{h}}$ at $\mathrm{r}=\mathrm{h}$, we obtain

$$
\frac{r_{0}}{h}=\frac{\tau_{0}}{\tau_{h}}=\tau, 0<\tau<1
$$

Taking $\mathrm{r}=\mathrm{r}_{\mathrm{n}}$ in Eqs. (3.1), (3.2) we get the plug core velocity as $u_{p}=\frac{(p+f)}{\mu}\left[\frac{r_{0}^{2}}{12}-\frac{h r_{0}}{2}+\frac{2}{3} h^{3 / 2} r_{0}^{1 / 2}-\frac{h^{2}}{4}\right]$ for $0 \leq r \leq r_{0}$

$$
u_{p}=\frac{(p+f) h^{2}}{\mu}\left[\frac{1}{4}+\frac{\tau_{0}^{2}}{2}-\frac{\tau_{0}}{2}\right] \text { for } 0 \leq r \leq r_{0}
$$

Plug core velocity for the Casson's fluid model is given by Eq. (15), and the socketbasespeed for the Bingham Plastic fluid model is given by Eq. (16).

The volumetric flow rate is defined by

$$
Q=2 r\left[\int_{0}^{r_{0}} u_{p} r d r+\int_{r_{0}}^{h} u r d r\right](17)
$$

Substituting Eq. $(11,12)$ and Eq. $(15,16)$ in Eq. (17) and integrating, we finally get

$Q=\frac{h^{3}}{2 \mu}(P+f)\left[\begin{array}{c}-\frac{1}{12 h}\left(\tau_{0}^{2}+1\right)+\tau_{0}^{\frac{5}{2}} h\left(4-\tau_{0}^{\frac{1}{2}}\right)+\frac{\tau_{0}}{(P+f)}\left(\frac{4}{3}\left(1-\tau_{0}^{3}\right)-2\left(1-\tau_{0}^{2}\right)\right) \\ -\frac{\sqrt[2]{2}}{3}\left(\frac{\tau_{0}}{(p+f)}\right)^{\frac{1}{2}} h^{\frac{1}{2}}\left(\frac{1}{7}\left(1-\tau_{0}^{\frac{7}{2}}\right)-\frac{1}{4}\left(1-\tau_{0}^{2}\right)\right)\end{array}\right]$

$Q=\frac{h^{3}}{\mu}(P+f)\left[\tau_{0}^{2} h\left(\frac{1}{4}+\frac{1}{4} \tau_{0}^{2}-\frac{\tau_{0}}{2}\right)+\frac{h}{4\left(1-\tau_{0}\right)}-\frac{h}{8}\left(1-\tau_{0}^{4}\right)+\frac{2 \tau_{0}}{(p+f)}\left(\frac{1}{3}\left(1-\tau_{0}^{3}\right)-\frac{1}{2}\left(1-\tau_{0}^{2}\right)\right)\right]$

$\lambda=-\frac{1}{Q} \int_{-1}^{1}\left[\begin{array}{l}-Q \mu+ \\ \tau_{0}^{2} h^{4}\left(\frac{1}{4}+\frac{1}{4} \tau_{0}^{2}-\frac{\tau_{0}}{2}+\frac{h^{4}}{4}\left(1-\tau_{0}\left(\frac{1}{3} h^{3}\left(1-\tau_{0}^{2}\right)-\frac{h^{3}}{2}\left(1-\tau_{0}^{2}\right)\right)\right.\right. \\ \left.\frac{h^{4}}{8}\left(1-\tau_{0}^{4}\right)\right)\end{array}\right]+f d z$

\section{Results and Discussion}

Stenosis is a severe cardiovascular disease. The irregular growth of stenosis affects the flow of blood in the arteries and which leads tosevere circulatory disorders. Stenoses are formed by the accumulation of fats/ lipids on the inner wall of the arteries. Stenosis developed in the arteries can cause several diseases like blood pressure, atherosclerosis, heart attack and brain hem- orrhage. The effects of various parameters on the resistance to flow are computed numerically by taking

$$
\frac{R^{*}(z)}{R_{0}}=\exp \left[\beta \mathrm{B}^{2}\left(\mathrm{z}-\mathrm{B}_{1}\right)^{2}\right]
$$

And $\mathrm{d}_{1}=\mathrm{L}_{1}=\mathrm{L}_{2}=0.2, \mathrm{~B}_{1}=0.8, \mathrm{~B}=1, \beta_{1}=0.01$.

Figure. $3-4$, gives the results for resistance to flow with the height of the secondary stenosis for different values of $\alpha$. It is found that the Casson's fluid model gives higher results in comparison to Bingham Plastic fluid. It is found that resistance to flow increases on increasing values of $\delta_{2}$ and increases for the decreasing values of $\alpha$ for the both fluid models ${ }^{[11,12]}$. Figures. 5 -6 , gives the results for resistance to flow with the height of the secondary stenosis for different values of $\alpha$ and $\tau$. It is found that the Casson's fluid model gives higher results in comparison to Bingham Plastic fluid. It is found that resistance to flow increases on increasing values of $\delta_{2}$ and $\tau$. It is also discovered that the resistance to flow increases for the decreasing values of $\alpha$ for the both fluid models ${ }^{[5,13]}$.

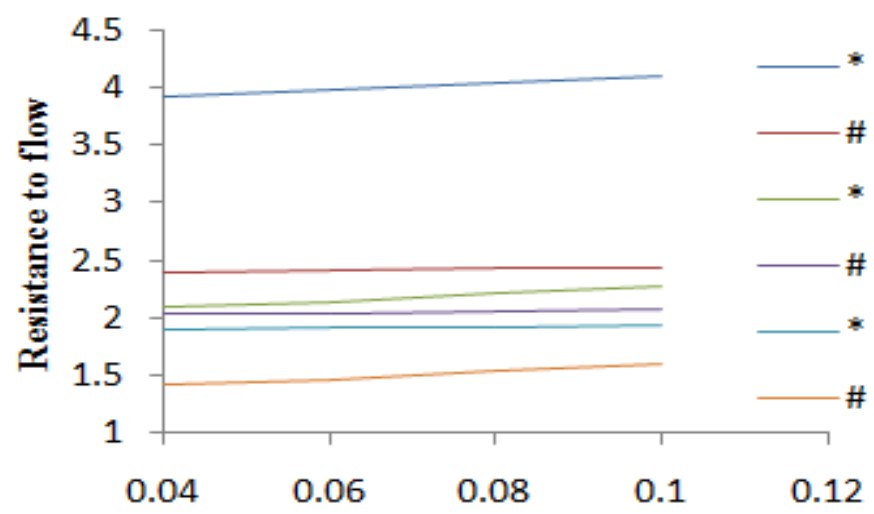

\section{Height of secondary stenosis $\delta_{2}$}

Figure 3: Variation of resistance to flow with respect to $\delta_{2}$ for different values of $\alpha$ When $\mathrm{F}=0.1, \delta_{1}=0$. ${ }^{*}$ for Casson fluid and \# for Bingham Plastic fluid.

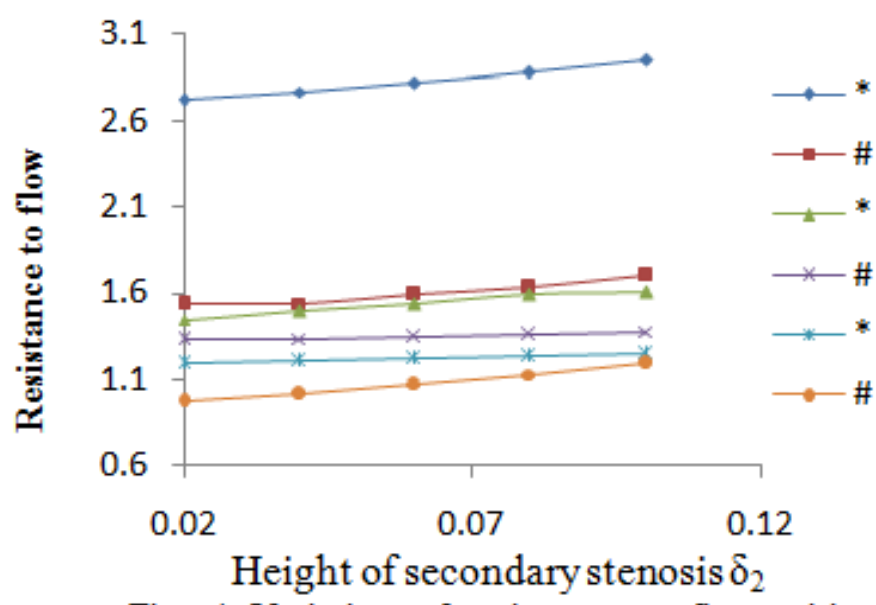

Figure 4: Variation of resistance to flow with respect to $\delta_{2}$ for different values of $\alpha$, When $\mathrm{F}=0.1, \delta_{1}=0.1$.

* for Casson fluid and \# for Bingham Plastic fluid. 


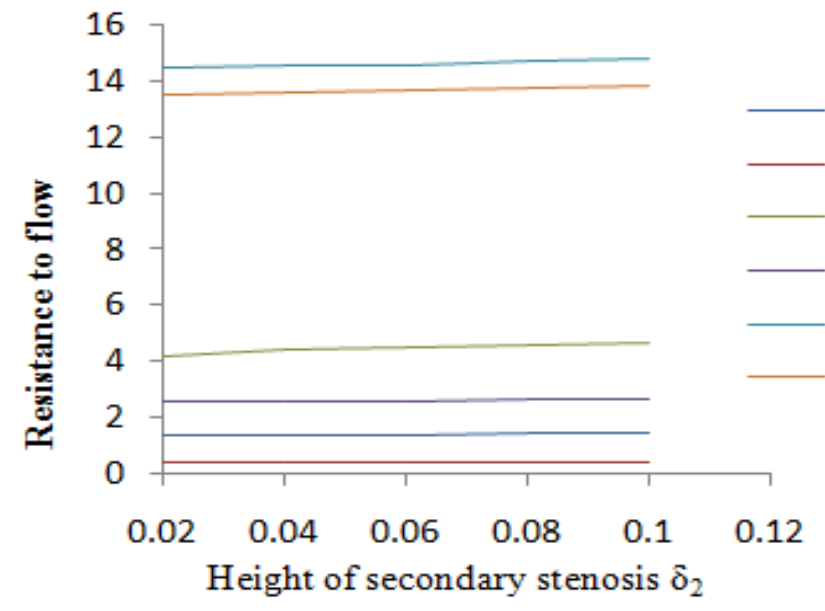

Figure 5: Variation of resistance to flow with respect to $\delta_{2}$ for different values of $\tau$, when, $\delta_{1}=0$.

* for Casson fluid and \# for Bingham Plastic fluid.

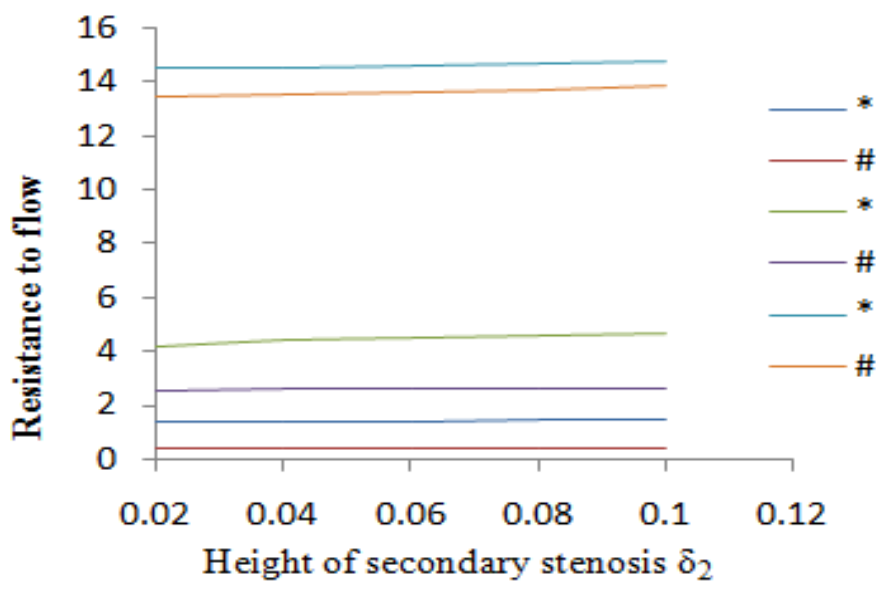

Figure 6: Variation of resistance to flow with respect to $\delta_{2}$ for different values of $\tau$, when, $\delta_{1}=0$.

* for Casson fluid and \# for Bingham Plastic fluid.

\section{Conclusion}

It is observed that the resistance to flow increases with the height of both the primary and secondary stenosis $\left(\delta_{1}, \delta_{2}\right)$ for both the fluid models. It is also noticed that the resistance to flow also decreases with the decreasing value of inclination $(\alpha)$ in Cassons fluid model and Bingham flexible fluid design. This comparison presents a better study to understand the flow characteristics of blood having multi-stenoses through an inclined tube of non-uniform cross-section. And the significance of aspirin to prevent the blood clotting.

\section{References}

1. Biswas, D., Ali, M. Two-layered mathematical model for blood flow in an asymmetric stenosed artery with velocity slip at the interface. (2014) Int J Math Arch 5(2): 293-301.

PubMed | CrossRef | Others

2. Karimi, A. Effect of stenoses shapes on the flow parameters in the stenosed artery for non-Newtonian fluids. (2010) Proceedings of the 37th National \& 4th International Conference on Fluid Mechanics and Fluid Power December 16-18.

PubMed $\mid$ CrossRef $\mid$ Others

3. Agarwal, R., Varshney, N.K. Slip velocity effect on MHD oscillatory blood flow through the stenosed artery. (2014) Adv Appl Sci Res 5(1): 84-90.

PubMed | CrossRef $\mid$ Others

4. Liepsch, D., Singh, M., Lee, M. Experimental analysis of the influence of stenotic geometry on steady flow. (1992) Biorheology 29(4): 419-431.

PubMed $\mid$ CrossRef $\mid$ Others

5. Mohan, V., Prashad, V., Varshney, N.K. Effect of inclination of an stenosed artery on Casson fluid flow with periodic body acceleration. (2013) Int J Adv Sci Tech Res 4(3): 365-371.

PubMed | CrossRef | Others

6. Bhatnagar, A., Srivastava, R.K., Singh, A.K. A numerical analysis of the effect of slip velocity and stenosis shape on the non-newtonian flow of blood. (2015) Int J Engg 28(3): 440-446.

PubMed | CrossRef $\mid$ Others

7. Mekheimer, Kh.S., Elkot, M.A. Mathematical modeling of unsteady flow of a Sisko fluid through an anisotropically tapered elastic arteries with time-variant overlapping stenosis. (2012) Appl Math Mod 36(11): 5393-5407.

PubMed | CrossRef | Others

8. Biswas, D., Chakrabarty, U.S. Pulsatile blood flow through a catheterized artery with an axially nonsymmetrical stenosis. (2010) Appl Math Sci 4(58): 2865 - 2880.

PubMed | CrossRef $\mid$ Others

9. Ellahi, R., Rahman, S.U., Gulzar, M.M., et al. A mathematical study of non-Newtonian micropolar fluid in arterial blood flow through the composite stenosis. (2014) Appl Math Inform Sci 8(4): 1567-1573.

PubMed | CrossRef $\mid$ Others

10. Sankar, A.R., Gunakala, S.R., Comissiong, D.M.G. Two-layered Blood Flow through a Composite Stenosis in the Presence of a Magnetic Field. (2013) Int J App Innov Engg Manag 2(12): 30-41. PubMed | CrossRef | Others

11. Rathod, V.P. Blood flow through stenosed inclined tubes with periodic body acceleration in the presence of magnetic field and its applications to cardiovascular diseases. (2014) Int J Res Engg Tech 3(3): 96-101.

PubMed | CrossRef $\mid$ Others

12. Sankar, D.S., Hemalatha, K. Non-linear mathematical models for blood flow through tapered tubes. (2007) Appl Math Comput 188(1): 567-582.

PubMed | CrossRef $\mid$ Others

13. Kumar, S., Diwakar, C. Blood flow resistance for a small artery with the effect of multiple stenoses and post stenotic dilatation. (2013) Int J Engg Sci Emerg Technol 6(1): 57-64.

PubMed $\mid$ CrossRef $\mid$ Others 